\title{
4Dimensional X Strain and 2Dimensional Speckle Tracking Echocardiographic Study: Normative Values of Strain Parameters of Left Ventricle and Tissue Doppler Imaging of Ascending Aorta in Healthy Adults -A Single Centre Indian Study
}

\author{
Akhil Mehrotra $^{1 *}$, Ajay Sharma ${ }^{2}$, Mohammad Shadab $^{2}$, Mukesh Srivastava $^{3}$, \\ Naveen Chandra ${ }^{4}$, Alok Kumar Singh ${ }^{5}$. \\ ${ }^{1}$ Ph.D in Cardiology, Texila American University, India \\ ${ }^{2}$ Prakash Heart Station and Diagnostics, Lucknow, India \\ ${ }^{3}$ Central Drug Research Institute, Lucknow, India \\ ${ }^{4}$ Vivekanand Hospital Lucknow, India \\ ${ }^{5}$ Heart India Journal, Varanasi, India
}

\begin{abstract}
Global longitudinal strain $(G L S)$ is a sensitive measure of $L V$ dysfunction and is better than EF at predicting CVD events and deaths. Recently 3D/4D/4D X strain speckle tracking echocardiography (STE) is used to analyse complex LV mechanics. Interestingly, HFpEF is related to both GLS and increased Aortic stiffness. TDI of ascending Aorta is an effective technique to assess Aortic stiffness. The aim of the present study is to establish normal values of TDI of AA by $2 D E$ and $4 D X$-strain volumetric and strain parameters of LV of healthy adults. 102 subjects were enrolled, 72 assessed by 2DE-GROUP-A, and 30 were analysed by $4 D X$-strain echocardiography-GROUP-B. Important TDI parameters of Aortic stiffness were $3.90 \pm 3.79 \& 5.23 \pm 10.55,(p=N S)$, in males \& females respectively and Aortic strain were $10.55 \pm 7.67 \%$ and $9.49 \pm 5.56 \%,(p=N S)$, in males \& females respectively. Volumetric data of EF were $64 \pm 7.0 \%$ \& $65 \pm 6.0 \%,(p=N S)$, in males \& females respectively and CO were $5.6 \pm 1.5 \mathrm{l} / \mathrm{min} \& 4.91 \pm 1.53 \mathrm{l} / \mathrm{min},(p=N S)$, in males \& females respectively. Moreover, $4 D$ $X$-strain STE indices of GLS being -17.29 $\pm 2.71 \&-19.00 \pm 3.51,(p=N S)$, in males \& females, respectively GCS being $-15.46 \pm 7.1 \&-14.12 \pm 6.15,(p=N S)$, in males \& females respectively and GRS being $-24.53 \pm 9.8 \&-21.93 \pm-8.81,(p=N S)$, in males \& females respectively. No previous data is available, making the research a singular experience.
\end{abstract}

Keywords: 2Dimensional Speckle Tracking, 4Dimensional X Strain echocardiography, Echocardiography, LV segmental strain, $4 D$ volumetric data.

\section{Introduction}

Left ventricular (LV) function can be evaluated using directional components of myocardial deformation or strain. Longitudinal LV strain, also referred to as global longitudinal strain (GLS), appears to be a sensitive measure of impaired LV systolic function [1-3] and has been shown in several studies to be better than ejection fraction at predicting cardiovascular disease events and death [4-7]. Recently, 3Dimensional Speckle Tracking Echocardiography (3D STE) has been introduced by applying speckle tracking technologies to 3D echocardiography images. Images are usually acquired using a matrix-array transducer from the apical position in a wideangled acquisition "full-volume" mode. In this

*Corresponding Author: sadhnamehrotra14@gmail.com 
mode, a number of wedge-shaped subvolumes are acquired over consecutive cardiac cycles during single breath-hold and stitched together to create one pyramidal volume sample. A major limitation of 3D STE to date is the temporal resolution of the volumetric pyramidal data sets. Usually, the rate of acquisition does not exceed 20-30 volumes/s, and, in most cases, to obtain a higher temporal resolution, the field of view needs to be considerably narrowed. By fusing 2D speckle tracking information obtained from standard apical $4 \mathrm{CH}, 2 \mathrm{CH}$, and $3 \mathrm{CH}$ views, $\mathrm{X}$ -
Strain $^{\mathrm{TM}}$ four-dimensional (4D) aims to make myocardial quantification imaging interpretation easier by the 3D/4D reconstruction of the $\mathrm{LV}$. The Beutel can be freely rotated, zoomed, and super imposed on the echocardiographic scanning planes to better evaluate the contractility properties of the LV, using a physiological tool to analyze the complex multidimensional LV mechanics [7], including a parallel assessment of myocardial regional and global function (Figure 1).

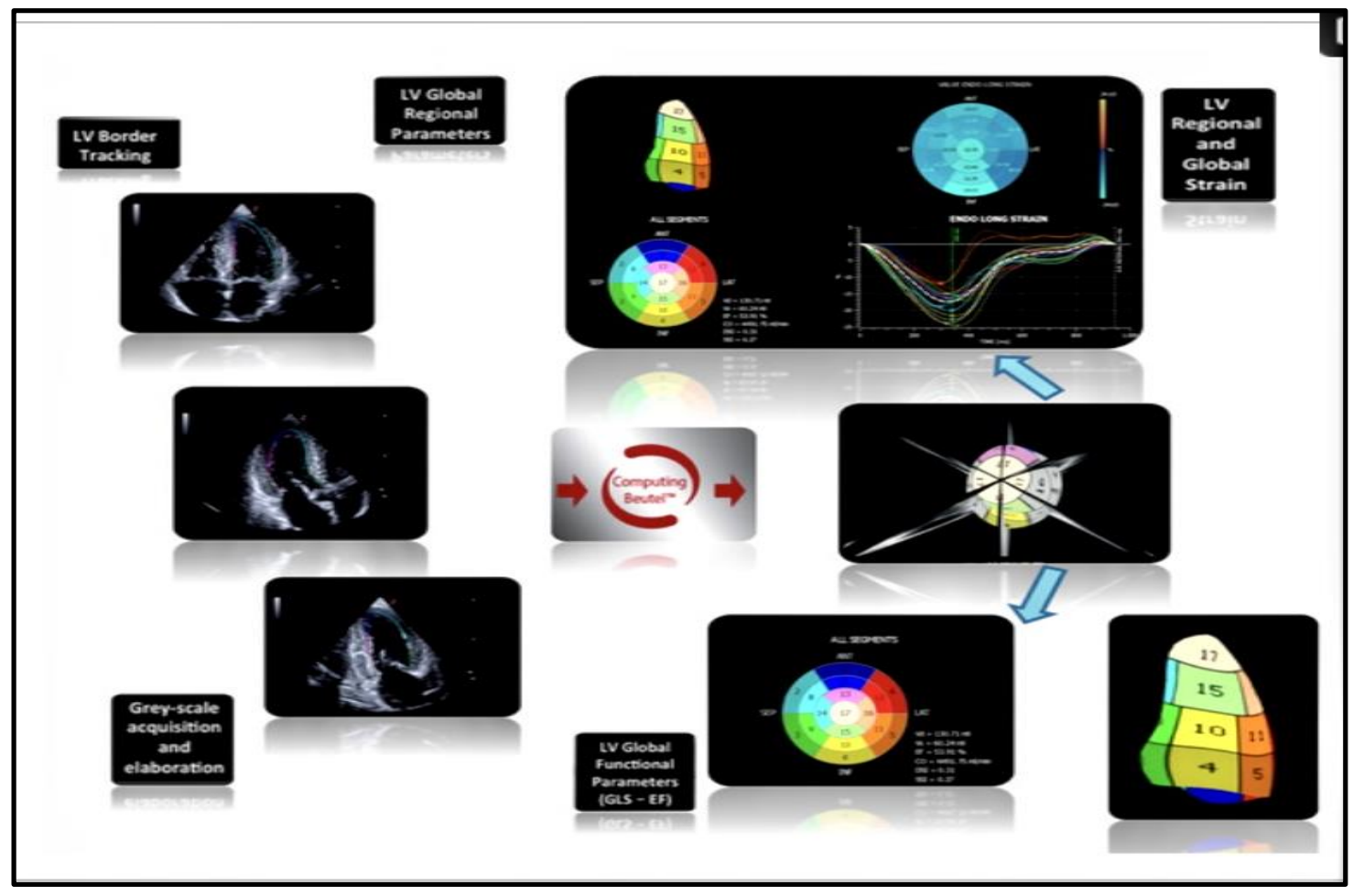

Figure 1. X Strain Global LV Analysis

Longitudinal shortening of the LV produces aortic displacement during systole [8-10] and stretches the ascending Aorta [11]. The force required to produce a longitudinal strain of the Aorta represents an often-overlooked form of direct mechanical load on the LV that may have important implications for the relation between aortic stiffness and LV systolic function, particularly in the long axis. [11, 12]. Alterations in both LV and aortic physiology may play an important role in predisposition to heart failure and especially heart failure with preserved ejection fraction (HFpEF). Whereas HFpEF is almost as common as heart failure with reduced ejection fraction, HFpEF has proven relatively refractory to treatment in a number of randomized clinical trials [13-15] underscoring the importance of efforts to better understand its pathophysiology. Interestingly, HFpEF has been related to both reduced GLS and increased aortic stiffness in a number of prior studies [3, 16-20]. Furthermore, both HFpEF and aortic stiffness are prevalent in older individuals, particularly women [16, 17] suggesting possible pathophysiological links between aortic stiffness and subclinical alterations in LV systolic 
function that may promote the development of HFpEF in susceptible individuals.

Several procedures have been used for the determination of aortic stiffness and or/distensibility, such as MRI, Angiography, applantation tonometry, Velocity vector imaging (VVI) [22-25]. But the vast majority of this technique was invasive and time-consuming and may require complex equipment and training. Tissue Doppler imaging (TDI) echocardiography of AA has been analysed in a number of studies and was found to be a useful method in the evaluation of elastic properties of Aorta $[26,30]$. Increased arterial stiffness index has been formerly determined in various patient groups, including those with $\mathrm{CAD}$, diabetes mellitus, overt hypothyroidism, and on different vascular beds and at different sites such as the radial artery, carotid artery, and Aorta [27-33]. As earlier stated, 4D XSTRAIN $^{\mathrm{TM}}$ echocardiography is a reliable, intuitive, affordable, and simple tool for quantification of regional myocardial function [7]. Studies regarding normal reference values of LV volumetric and strain parameters by $\mathrm{X}$ strain 4DE and TDI indices of AA by 2DE in healthy adult population could not be found despite exhaustive and thorough review of the literature.

Hence, we embarked on this study of Indian healthy adults without overt cardio-vascular disease, with the aims to establish normal values of LV volumetric and strain parameters by 4D X strain echocardiography and moreover of TDI parameters of AA by $2 \mathrm{D}$ echocardiography. To the best of our knowledge, there is no study published till date on normal reference values of volumetric and strain parameters of LV by $4 \mathrm{D} X$ strain echocardiography and neither any on TDI parameters of AA by 2DE, in the healthy adult population and, more importantly, in Indian subsets.

\section{Materials \& Methods}

\section{Study Population \& Design}

The present study was performed at Prakash Heart Station \& Diagnostic, Lucknow, India an approved centre of Texila American University for the current Ph.D. Cardiology program of the author. We state that our study confirms to the ethical guidelines of the 1975 declaration of Helsinki and that informed consent has been obtained from the study participants (or their guardians), and final approval was done by our Prakash Heart Station \& Diagnostic Institutions' Ethical Committee.

The study comprised of 426 healthy adult subjects from which 324 cases were excluded due to inferior image quality, and 102 participants were finally enrolled for the study after a careful selection process, during a period of spanning for 7 months from May to November 2021.

Healthy adults of age group 18-60 years, of either sex, were included if they were asymptomatic, free from overt cardiovascular disease, not receiving any drugs, non-smoker, non-tobacco chewer, non-diabetic, nonhypertensive according to JNC-8 guidelines, having normal thyroid and lipid profile, normal resting ECG in Sinus Rhythm with a normal 2 Dimensional color echocardiography and Treadmill Stress ECG with a normal physical examination, BMI- 23 or less, waist- size $85 \mathrm{~cm}$ or less in men and $80 \mathrm{~cm}$ or less in women. Those individuals were excluded if there was the presence of thyroid disease, valvular heart disease, history of cardiac rhythm abnormalities, heart failure systemic hypertension, and significant pulmonary hypertension. Moreover, the presence of diabetes mellitus, neurological or psychiatric illness, malignany, CAD Aortic root abnormalities, and aortic dilatation lead to the exclusion of such participants from the present study.

\section{Biochemical \& Hormonal Assessment}

Blood samples were withdrawn, in the morning, after 12 hours of overnight fasting for HBAIC, T3, T4, TSH, Serum creatinine, Serum uric acid, Total cholesterol (TC), Triglycerides (TG) \& high-density cholesterol (HDL-C). Serum Low-density Lipoprotein cholesterol 
(LDL-C) was calculated according to Freidwald's formula [34].

\section{Echocardiography Imaging}

In the current study, 2Dimensional echocardiography system of GE HEALTH CARE -VIVID T8 was utilized for comprehensive assessments of cardiac functions in left lateral decubitus position for M-MODE, 2D mode, Doppler, Global Longitudinal Strain analysis of LV by Speckle Tracking Echocardiography (STE) \& Tissue Doppler Imaging of Ascending Aorta from May 1 September 9, 2021, and the data of the enrolled 72 healthy subjects was obtained (2D group Group A). From September 10, 2021 - Nov 30, 2021, 30 additional healthy subjects were enrolled for a similar exhaustive evaluation of cardiac functions on MY LAB X7 4D X STRAIN echocardiography machine of ESAOTE, ITALY (4D X STRAIN group GROUP B). In addition to the procurement of data as in Group A, GLS, Global circumferential strain (GCS), strain rate (GCSR), Global Radial strain (GRS) strain rate (GRSR), and volumetric data by 4D X Strain echocardiography was further derived. The study on both the echocardiography machines was performed with consistent system presets, according to the prespecified protocols $[35,36]$.

A minimum of 3 cardiac cycles were recorded. Standard LV APICAL views (APLAX, 4CH \& $2 \mathrm{CH}$ views) were acquired, avoiding foreshortening with a frame rate of 50 - 80 frames/sec, thus compatible with speckle tracking analysis. For TDI, images were obtained from LV septal and lateral MV annulus walls in $4 \mathrm{CH}$ views and from the superior wall of ascending Aorta $3 \mathrm{~cm}$ above the aortic valve in the parasternal long-axis view. Similarly, 3 $\mathrm{cm}$ above the aortic valve, systolic and diastolic inner diameters of as ascending Aorta were recorded by M-MODE echocardiography. Aortic systolic diameter (AOS) and diastolic aortic diameter (AOD) were measured [Figure 2]. Distensibility and stiffness index of the ascending Aorta were calculated by using the following formula's [37- 40]:

1. AORTIC DISTENSIBILITY $=2 \mathrm{X}$ AOSAOD/[(SBP-DBP) X AOD (10-6 cm2 dyn1)].

2. AORTIC STIFFNESS INDEX: $\ln$ (SBP/DBP)/ [ (AOS - AOD)/AOD] (pure number),

3. $\ln =$ natural logarithm.

4. AORTIC PULSATILE CHANGE $=$ AOS AOD $(\mathrm{cm})$.

5. AORTIC SYSTOLIC INDEX will be estimated by dividing AOS, AOD and pulsatile.

6. AORTIC DIASTOLIC INDEX change by BSA respectively.

7. AORTIC PULSATILE INDEX.

8. ELASTICITY MODULUS $=(\mathrm{SBP}-\mathrm{DBP}) /$ [(AOS - AOD $) /$ AOD] $(\mathrm{Pa})$.

9. AORTIC STRAIN $=(\mathrm{SAO}-\mathrm{AOD}) \mathrm{X} 100 /$ $\operatorname{AOD}(\%)$.

Following data was estimated by TDI of the superior wall of ascending aorta - (Figure - 3).

1. SAO - Aortic superior wall velocity in systole- will be calculated at the same point used in M-mode measurement.

2. EAO- Early diastolic velocity.

3. AAO- late diastole velocity.

LV myocardial deformation was analysed offline by the Speckle Tracking software package.

1. 72 subjects in GROUP A were analysed by GE-VIVID T8 2D Echocardiography software package AFI 2.0 echopac version 202. The transducer used was adult probe $35 \mathrm{c}-\mathrm{RS}(1.3-4.0 \mathrm{Mhz})$.

2. 30 subjects in GROUP B were analysed by $\begin{array}{lllll}\text { MYLAB } & \mathrm{X} 7 & 4 \mathrm{D} & \mathrm{X} & \text { STRAIN }\end{array}$ echocardiography software package $\mathrm{X}$ STRAIN TM advanced technology with TOMTEC GMGH 3D/4D rendering and Beutel $^{\mathrm{TM}}$ computation compatibilities [55]. Imaging was performed by $1-5 \mathrm{Mhz}$ electronic single-crystal array transducer. Speckle Tracking Echocardiography (STE) 
was performed to analyse appropriate images, acquired, and captured according to the standardized protocol [35, 36]- (Figure $4,5)$.

\section{Statistical Methods}

The data were summarized as mean $\pm \mathrm{SD}$. The $95 \%$ confidence interval (CI) of the mean was also calculated. The mean of male and female was tested by t-test for independent groups. The level of significance used was 0.05 . A higher t- value having a probability smaller than 0.05 was marked significant. A p-value smaller than 0.01 was marked highly significant.

\section{Result}

The study comprised of 426 healthy adults, from which 324 were excluded due to inferior image quantity on echocardiography. 102 subjects were finally enrolled for the study after a careful selection process, during a period spanning 7 months from May - November 2021.

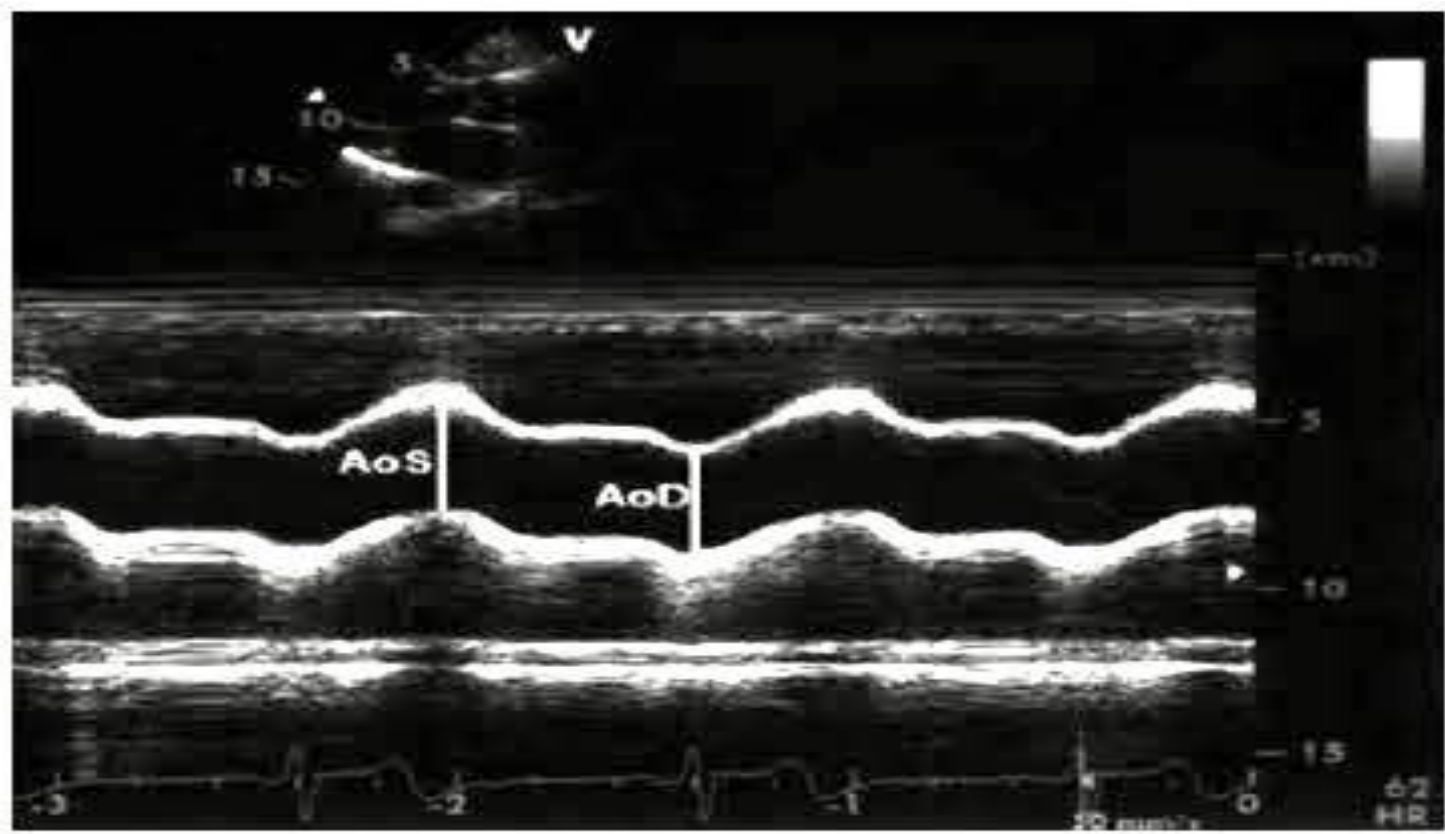

Figure 2. M Mode of Ascending Aorta

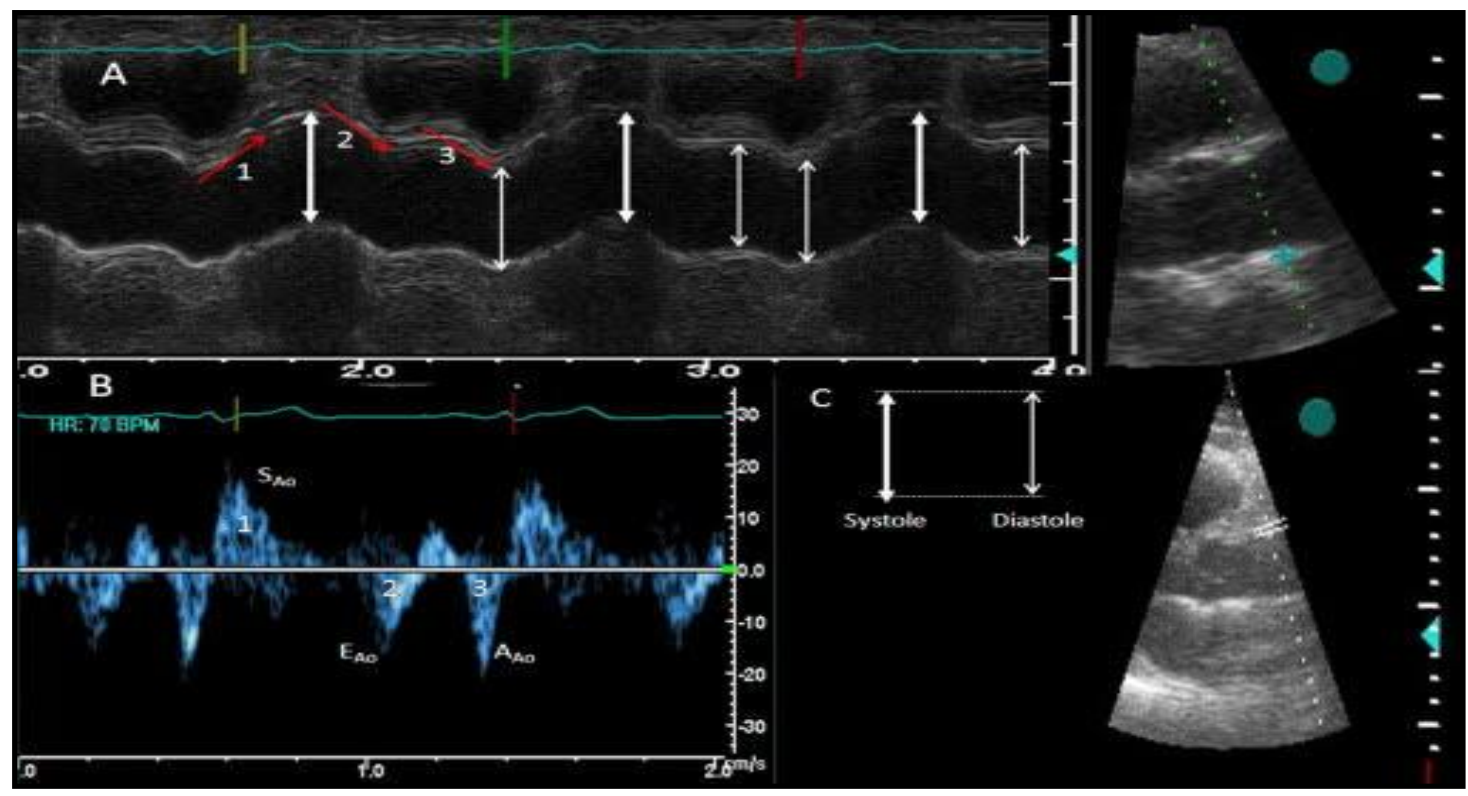

Figure 3. M-Mode and TDI of Ascending Aorta 


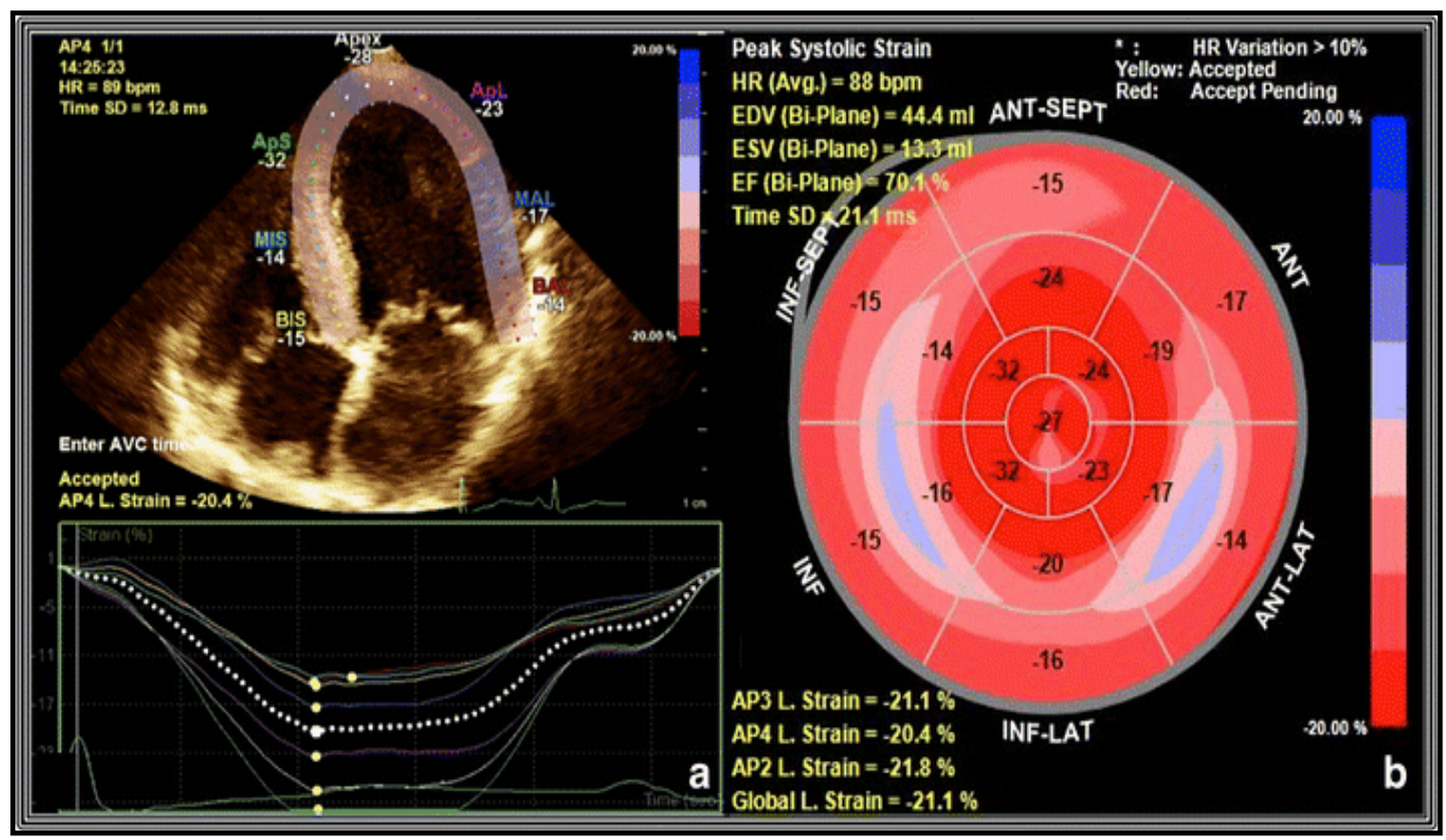

Figure 4. Speckle Tracking Echocardiography Images

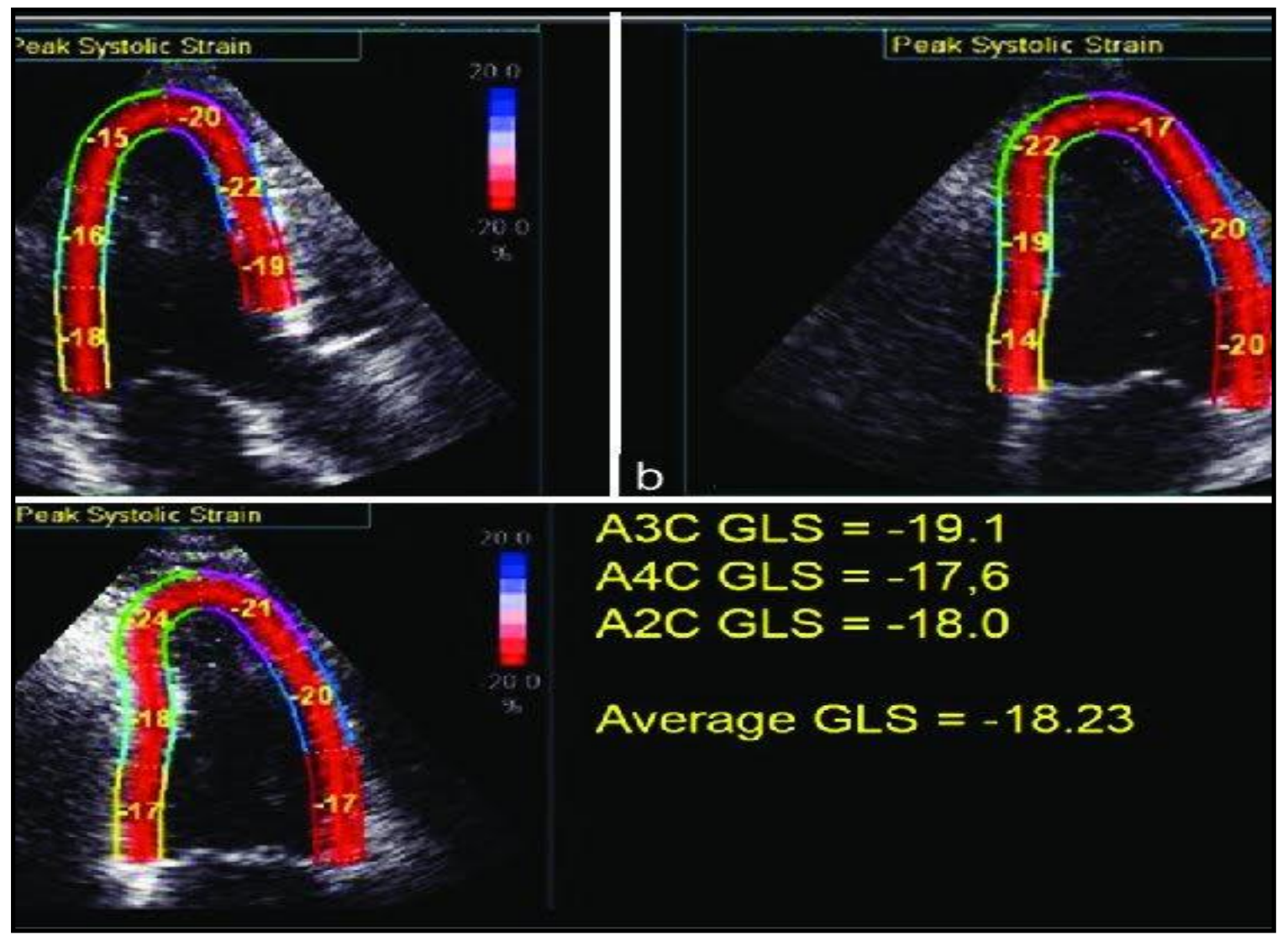

Figure 5. Speckle Tracking Echocardiography Images

Table 1 shows the characteristics of the study population of the 102 participants 72 consisted of the 2D group-Group A, and additionally, 30 subjects constituted the 4D group -Group B. In group A there are 44 males (age 32.55 \pm 9.63 years) and 28 females (age 29.11 \pm 11.83 years). In group B, there are 16 males (age 38.81 \pm 12.94 years) and 14 females (age $38.50 \pm 11.65$ years). 


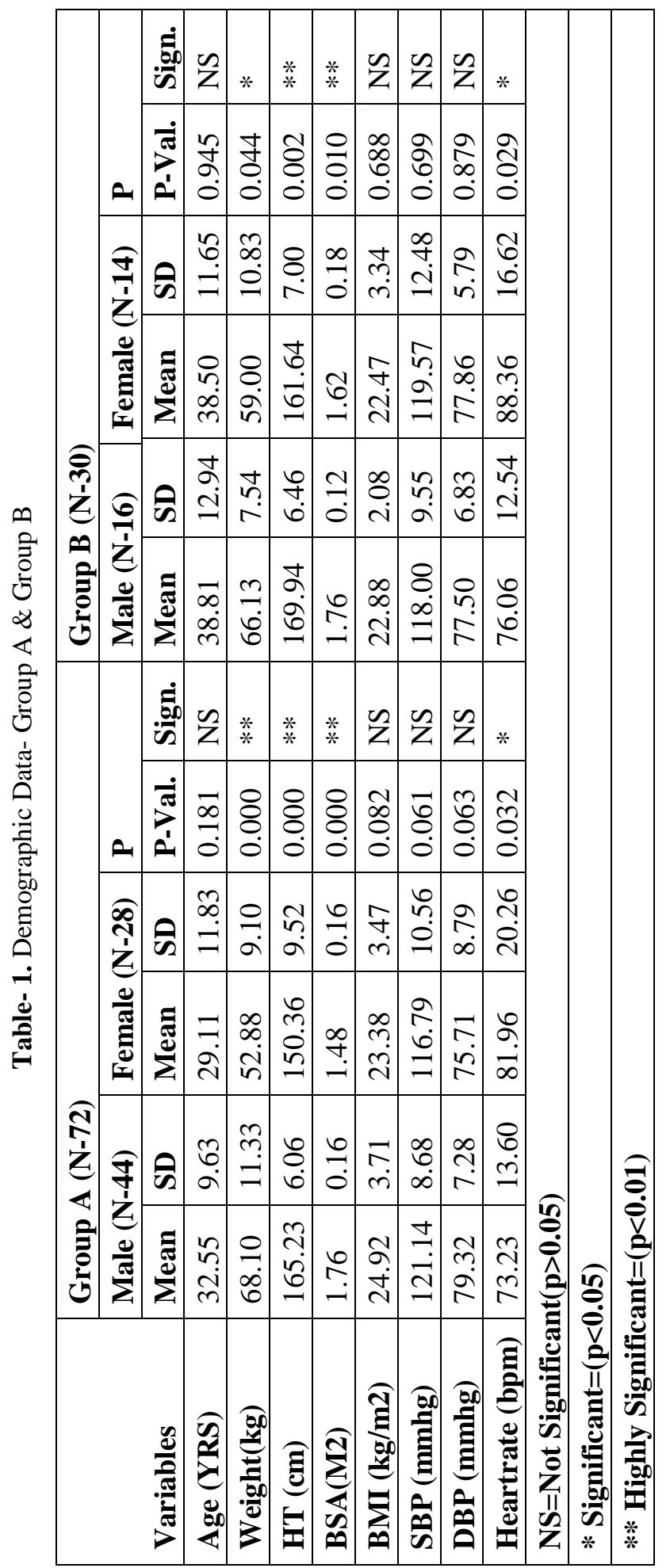

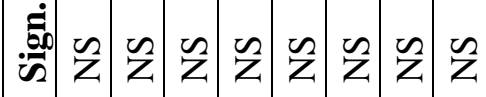

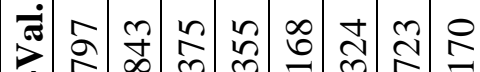

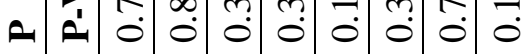

至 की

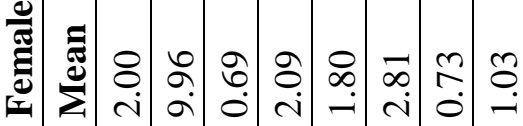

ิิ

$\infty$

흔

施

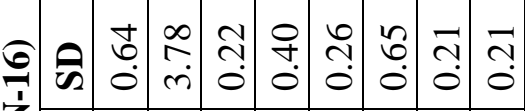

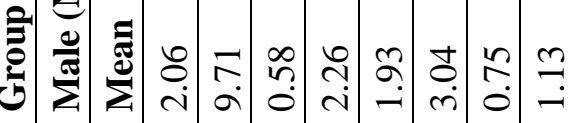

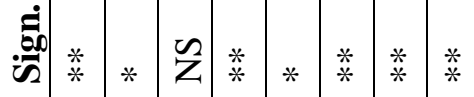

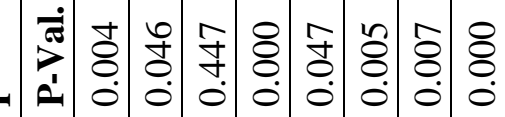

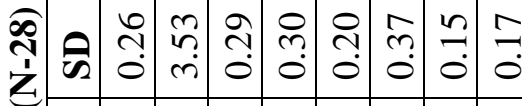

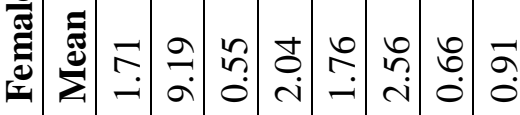

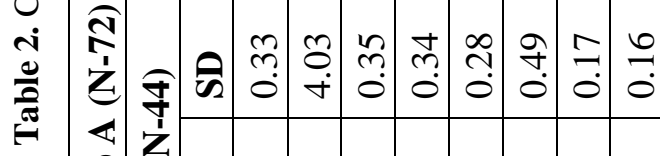

言站离

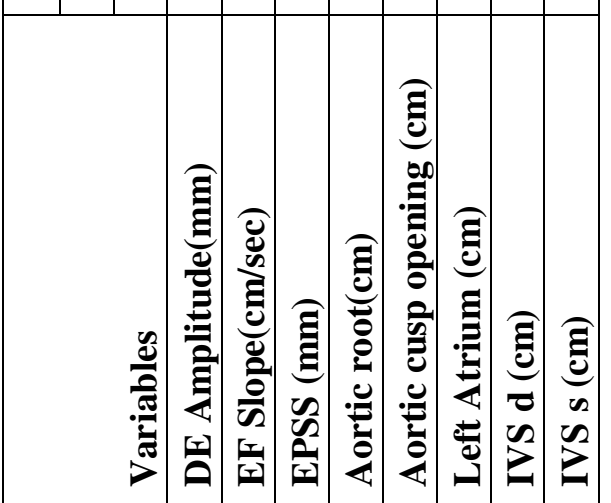




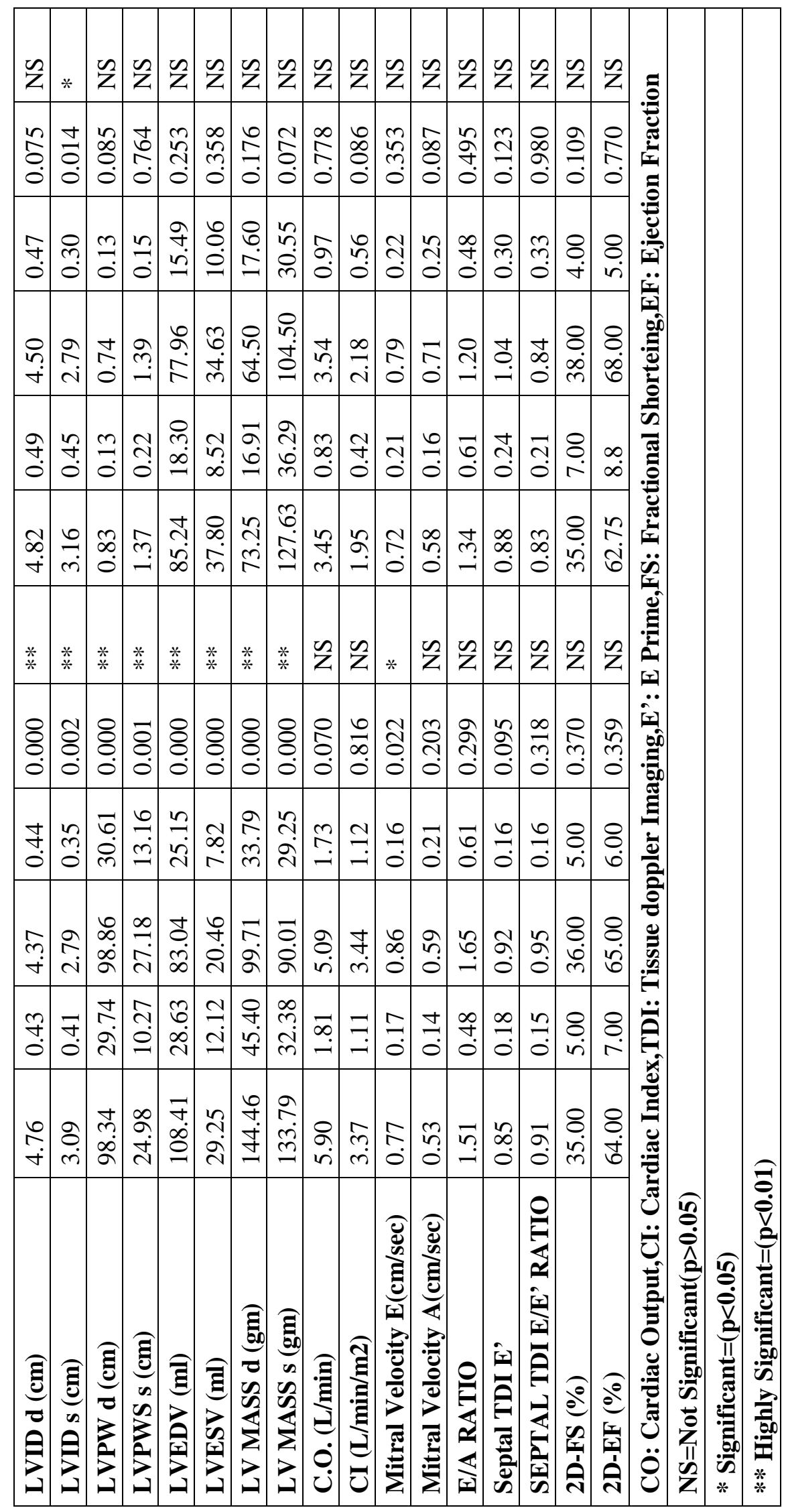


Table 2. Comprising of the conventional 2D echocardiographic data. In group A the LVEDV is $108.41 \pm 28.63 \mathrm{ml}$ in males $83.04 \pm 25.15 \mathrm{ml}$ in females ( $\mathrm{p}<0.01$ ), LV Mass is $144.46 \pm 45.40$ $\mathrm{gm}$ in diastole in males and $99.71 \pm 33.79 \mathrm{gm}$ in females $(\mathrm{p}<0.01)$, Cardiac output $(\mathrm{CO})$ being $5.90 \pm 1.81 \mathrm{l} / \mathrm{min}$ in males and $5.09 \pm 1.73 \mathrm{l} / \mathrm{min}$ in females ( $\mathrm{p}=\mathrm{NS}$ ) and EF is $64 \pm 7 \%$ in males and $65 \pm 6 \%$ in females $(\mathrm{p}=\mathrm{NS})$. In group $\mathrm{B}$, the LVEDV is $85.24 \pm 18.30 \mathrm{ml}$ in males and $77.96 \pm 15.49 \mathrm{ml}$ in females ( $\mathrm{p}=\mathrm{NS}$ ), LV Mass in diastole being $73.25 \pm 16.91 \mathrm{gm}$ in males and $64.80 \pm 17.60 \mathrm{gm}$ in females ( $\mathrm{p}=\mathrm{NS}$ ), $\mathrm{CO}$ is $3.45 \pm 0.83 \mathrm{~L} / \mathrm{min}$ in males and $3.54 \pm 0.97$ $\mathrm{L} / \mathrm{min}$ in females $(\mathrm{p}=\mathrm{NS}$ ) and $\mathrm{EF}$ is $62.75 \pm 8.8$ $\%$ in males and $68 \pm 5 \%$ in females $(\mathrm{p}=\mathrm{NS})$.

In Table 3. data of various parameters of TDI of AA and GLS of LV are enumerated in detail. In group, A pulsatile change, Aortic distensibility, Aortic stiffness index, Aortic pulsatile index, Aortic systolic and diastolic index, Aortic strain, and elasticity modulus did not reveal any significance in their values when the data of male subjects was compared to females $(\mathrm{p}=\mathrm{NS})$. However, the Aortic diastolic diameter (AOD) \& Systolic diameter (AOS) were significantly higher in males when compared with females. The AOD \& AOS in males being $2.79 \pm 0.45 \mathrm{~cm}$ and $3.05 \pm 0.49 \mathrm{~cm}$ respectively, when compared to females, who had a AOD \& AOS of $2.49 \pm 0.37 \mathrm{~cm}$ and 2.72 $\pm 4.40 \mathrm{~cm}$ respectively ( $<<0.01$ ). Furthermore, the average GLS values in group A males is $16.64 \pm 1.90 \%$ and $-17.87 \pm 2.1 \%$ in females suggesting that GLS values is higher in healthy adult females. ( $p<0.05$ ).

Likewise, elaborate data values of a various parameter of TDI of AA GLS of LV of Group B is presented. It is important to note that the values are not significantly different in between male $\&$ female subjects $(\mathrm{p}=\mathrm{NS})$.

In Table 4. 2D volumetric data of Group A and 4D volumetric data of Group B are summarized. The Group A values of LVEDV, $\mathrm{EF}, \mathrm{CO}$ have already been mentioned earlier while discussing Table 2. 4D volumetric data of group B shows the sphericity index values in males is $0.44 \pm 0.13$ and $0.37 \pm 0.15$ in diastole $\&$ systole, respectively. In females the sphericity index values are $0.39 \pm 0.09$ and $0.33 \pm 0.11$ in diastole and systole ( $\mathrm{p}=\mathrm{NS})$, LVEDV being $85.24 \pm 18.30 \mathrm{ml}$ in males and $77.96 \pm 15.49 \mathrm{ml}$ in female ( $\mathrm{p}=\mathrm{NS}$ ) LVESV being $37.80 \pm 8.5 \mathrm{ml}$ in males and $34.63 \pm 10.06 \mathrm{ml}$ in females $(\mathrm{p}=$ NS) and EF being $55.56 \pm 5.53 \%$ in males and $56.21 \pm 6.58 \%$ in females $(\mathrm{p}=\mathrm{NS})$, respectively. 


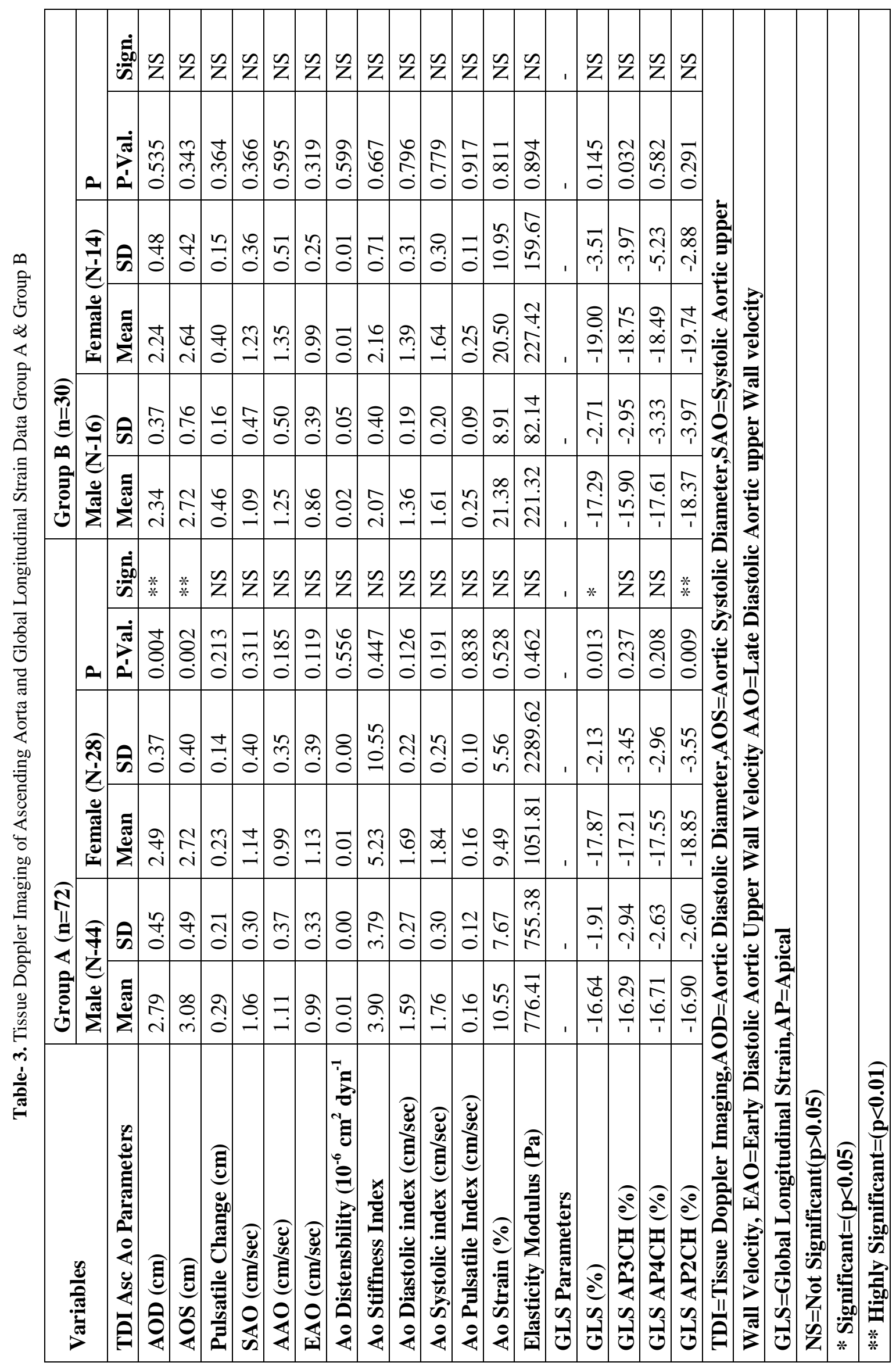




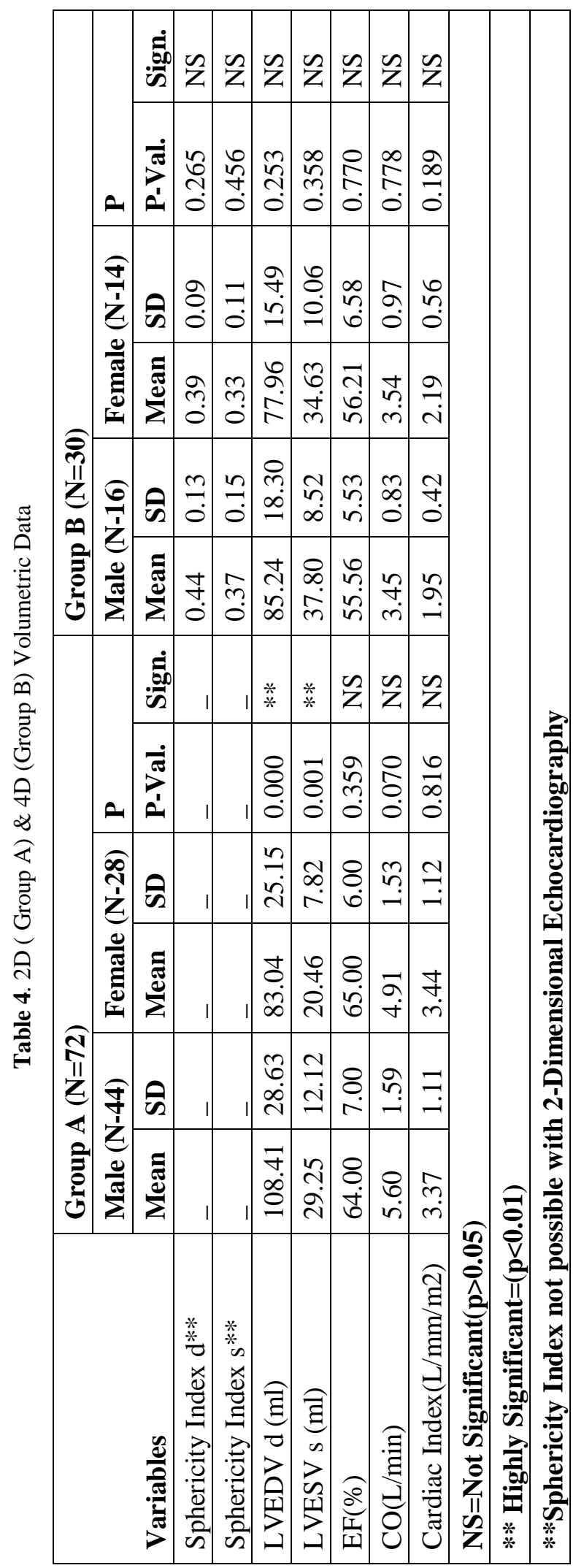


Table 5. consists of segmental strain data of 16 segment models of GLS of Group A. Largely, there is no significant difference in values of male $\&$ female subsets $(\mathrm{p}=\mathrm{NS})$.

Table-5. LV Segmental Strain Data-Group A (N=58) **

\begin{tabular}{|c|c|c|c|c|c|c|}
\hline \multirow[b]{2}{*}{ Variables } & \multicolumn{2}{|c|}{ Male (N-35) } & \multicolumn{2}{|c|}{ Female (N-23) } & \multicolumn{2}{|l|}{$\mathbf{P}$} \\
\hline & Mean & SD & Mean & SD & P-Val. & Sign \\
\hline \multicolumn{7}{|l|}{ AVC } \\
\hline GLS Avg (\%) & -16.64 & -1.91 & -17.87 & -2.13 & 0.013 & $*$ \\
\hline APLAX $(\%)$ & -16.30 & -2.95 & -17.21 & -3.45 & 0.237 & NS \\
\hline $\mathrm{AP} 4 \mathrm{CH}(\%)$ & -16.71 & -2.63 & -17.55 & -2.96 & 0.208 & NS \\
\hline $\mathrm{AP} 2 \mathrm{CH}(\%)$ & -16.90 & -2.60 & -18.85 & -3.55 & 0.009 & $* *$ \\
\hline \multicolumn{7}{|l|}{ AP 4CH } \\
\hline Basal sep (\%) & -17.03 & -4.82 & -17.35 & -8.86 & 0.860 & NS \\
\hline Mid sep (\%) & -20.94 & -3.83 & -17.91 & -9.03 & 0.083 & NS \\
\hline Ap sep (\%) & -17.63 & -4.48 & -15.78 & -7.82 & 0.258 & NS \\
\hline Basal lat(\%) & -17.91 & -5.99 & -18.70 & -8.22 & 0.677 & $\mathrm{NS}$ \\
\hline Mid lat (\%) & -16.94 & -5.09 & -20.04 & -5.15 & 0.028 & $*$ \\
\hline Ap lat $(\%)$ & -10.66 & -5.48 & -13.74 & -7.02 & 0.066 & NS \\
\hline \multicolumn{7}{|l|}{ AP 2CH } \\
\hline Basal inf $(\%)$ & -19.00 & -5.69 & -21.30 & -6.65 & 0.164 & NS \\
\hline Mid inf (\%) & -21.94 & -5.30 & -24.17 & -5.49 & 0.128 & NS \\
\hline Apical inf $(\%)$ & -18.71 & -5.50 & -20.09 & -5.42 & 0.354 & NS \\
\hline Basal ant (\%) & -19.11 & -4.85 & -22.43 & -7.81 & 0.050 & $*$ \\
\hline Mid ant (\%) & -16.74 & -5.35 & -16.30 & -8.55 & 0.811 & NS \\
\hline Ap ant (\%) & -11.23 & -6.62 & -10.57 & -6.23 & 0.704 & NS \\
\hline \multicolumn{7}{|l|}{ APLAX } \\
\hline Basal post $(\%)$ & -14.51 & -7.03 & -19.70 & -8.68 & 0.015 & NS \\
\hline Mid Post (\%) & -17.94 & -7.09 & -20.39 & -4.65 & 0.150 & NS \\
\hline Apical post $(\%)$ & -13.86 & -6.18 & -13.70 & -6.15 & 0.923 & NS \\
\hline Basal ant (\%) & -19.54 & -5.67 & -15.17 & -10.62 & 0.046 & $*$ \\
\hline Mid ant $(\%)$ & -17.11 & -6.24 & -15.09 & -8.67 & 0.305 & NS \\
\hline Ant Ap sep. (\%) & -10.20 & -7.05 & -11.57 & -6.65 & 0.464 & NS \\
\hline \multicolumn{7}{|c|}{ AVC=Aortic Valve Closure } \\
\hline \multicolumn{7}{|c|}{$\begin{array}{l}* * \text { Out Of } 72 \text { healthy subjects segmental strain data of only } 58 \text { subjects } \\
\text { could be properly procured during acquisition. }\end{array}$} \\
\hline \multicolumn{7}{|c|}{ NS=Not Significant $(p>0.05)$} \\
\hline \multicolumn{7}{|c|}{$*$ Significant $=(\mathbf{p}<0.05)$} \\
\hline \multicolumn{7}{|c|}{$* *$ Highly Significant $=(\mathbf{p}<0.01)$} \\
\hline
\end{tabular}

In Table 6, 17 segment model of GLS inclusive of LV apex is outlined, and overall, the values are insignificant when comparing males and females $(\mathrm{p}=\mathrm{NS})$. 
Table-6. LV Segmental Strain Data-Group B(N=30)

\begin{tabular}{|c|c|c|c|c|c|c|}
\hline \multirow{2}{*}{ Variables } & \multicolumn{2}{|c|}{ Male (N-16) } & \multicolumn{2}{|c|}{ Female (N-14) } & \multicolumn{2}{|l|}{$\mathbf{P}$} \\
\hline & Mean & SD & Mean & SD & P-Val. & Sign. \\
\hline \multicolumn{7}{|l|}{ AVC } \\
\hline GLS Avg (\%) & -17.29 & -2.71 & -19.00 & -3.51 & 0.145 & NS \\
\hline APLAX (\%) & -15.90 & -2.95 & -18.75 & -3.97 & 0.032 & NS \\
\hline $\mathrm{AP} 4 \mathrm{CH}(\%)$ & -17.61 & -3.33 & -18.49 & -5.23 & 0.582 & NS \\
\hline AP $2 \mathrm{CH}(\%)$ & -18.37 & -3.97 & -19.74 & -2.88 & 0.291 & NS \\
\hline Basal ant (\%) & -20.58 & -5.90 & -24.25 & -6.52 & 0.117 & NS \\
\hline Basal ant septal (\%) & -16.06 & -5.48 & -20.05 & -6.68 & 0.083 & NS \\
\hline Basal septal (\%) & -16.99 & -8.41 & -17.99 & -5.77 & 0.711 & NS \\
\hline Basal Inferior $(\%)$ & -22.00 & -7.79 & -23.34 & -7.70 & 0.640 & NS \\
\hline Basal posterior $(\%)$ & -20.57 & -6.20 & -25.10 & -6.30 & 0.058 & NS \\
\hline Basal Lateral (\%) & -21.04 & -6.49 & -18.97 & -7.93 & 0.438 & NS \\
\hline Mid Anterior (\%) & -13.98 & -5.07 & -18.40 & -6.44 & 0.045 & $*$ \\
\hline Mid ant septal (\%) & -16.77 & -4.21 & -18.01 & -4.66 & 0.449 & NS \\
\hline Mid Septum (\%) & -18.62 & -4.12 & -19.67 & -3.83 & 0.476 & NS \\
\hline Mid inf $(\%)$ & -20.48 & -5.16 & -19.48 & -4.49 & 0.581 & NS \\
\hline Mid Posterior (\%) & -15.74 & -6.03 & -18.59 & -4.20 & 0.149 & NS \\
\hline Mid Lateral (\%) & -14.52 & -4.56 & -18.48 & -5.62 & 0.042 & $*$ \\
\hline Apical ant (\%) & -13.90 & -5.05 & -16.09 & -6.49 & 0.309 & NS \\
\hline Apical septal (\%) & -25.99 & -6.49 & -27.78 & -9.39 & 0.544 & NS \\
\hline Apical inf $(\%)$ & -19.04 & -4.61 & -18.80 & -5.65 & 0.901 & NS \\
\hline Apical lateral (\%) & -21.07 & -7.18 & -23.34 & -10.96 & 0.504 & NS \\
\hline Apex $(\%)$ & -16.09 & -3.67 & -17.65 & -5.30 & 0.350 & NS \\
\hline \multicolumn{7}{|c|}{ AVC=Aortic Valve Closure } \\
\hline \multicolumn{7}{|c|}{ NS=Not Significant $(p>0.05)$} \\
\hline$*$ Significant $=(p<0$ & & & & & & \\
\hline
\end{tabular}

Table 7. is displaying Global circumferential strain (GCS), strain rate (GCSR), Global Radial strain (GRS) and strain rate (GRSR) of LV. GCS values at mitral valve and papillary muscle level are $-15.46 \pm 7.10 \% \&-20.28 \pm 6.78 \%$ respectively in males, and $-14.12 \pm 6.15 \%$ \& $19.69 \pm 7.98 \%$ respectively, in females $(p=N S)$.
GRS values at the mitral valve and papillary muscles level are $-24.53 \pm 9.82 \% \&-24.40 \pm$ $10.52 \%$ respectively in males, and $-21.93 \pm 8.81$ $\% \&-22.12 \pm 11.00 \%$ respectively in females (p $=$ NS). Likewise, the GCSR \& GRSR values were insignificant in male $\&$ female subsets ( $\mathrm{p}=$ NS).

Table-7. 4-Dimensional X Strain and Strain rate Data - Group-B (N=30)

\begin{tabular}{|c|c|c|c|c|c|c|}
\hline \multirow{2}{*}{ Variables } & \multicolumn{2}{|c|}{ Male $(n=16)$} & \multicolumn{2}{|c|}{ Female $(n=14)$} & \multicolumn{2}{|l|}{$\mathbf{P}$} \\
\hline & Mean & SD & Mean & SD & P-Val. & Sign. \\
\hline GLS (\%) & -17.29 & -2.71 & -19.00 & -3.51 & 0.145 & NS \\
\hline GCS & 0 & 0 & 0 & 0 & & \\
\hline at mv level $(\%)$ & -15.46 & -7.10 & -14.12 & -6.15 & 0.587 & NS \\
\hline at pap level (\%) & -20.28 & -6.78 & -19.69 & -7.98 & 0.831 & NS \\
\hline
\end{tabular}




\begin{tabular}{|l|l|l|l|l|l|l|}
\hline GRS & 0 & 0 & 0 & 0 & & \\
\hline at mv level (\%) & -24.53 & -9.82 & -21.93 & -8.81 & 0.455 & $\mathrm{NS}$ \\
\hline at pap level (\%) & -24.40 & -10.52 & -22.12 & -11.00 & 0.567 & $\mathrm{NS}$ \\
\hline GCSR & & & & & & \\
\hline at mv level (1/sec) & 1.78 & 0.62 & 1.97 & 0.68 & 0.433 & $\mathrm{NS}$ \\
\hline at pap level (1/sec) & 1.88 & 0.59 & 2.09 & 0.64 & 0.353 & $\mathrm{NS}$ \\
\hline GRSR & & & & & & \\
\hline at mv level (1/sec) & 2.87 & 0.97 & 2.70 & 1.04 & 0.649 & $\mathrm{NS}$ \\
\hline at pap level (1/sec) & 2.30 & 0.58 & 2.89 & 1.20 & 0.090 & NS \\
\hline GLS: global Longitudinal Strain GCS=Global circumferential Strain,GRS=Global Radial Strain \\
\hline GCSR=Global circumferential Strain rate, GRSR=Global Radial Strain rate \\
\hline
\end{tabular}

\section{Discussion}

Studies reporting a comprehensive assessment of LV strain in the healthy adult population, including data of TDI of ascending Aorta and myocardial deformation and the impact of age and sex on these parameters, are scarce. Furthermore, the publications on reference values of TDI of Ascending Aorta, 4D volumetric and 4D X Strain data of GLS, GCS, GCSR, GRS, GRSR in healthy individuals could not be found even after vigourous \& profound review of the literature. Perhaps this is the first research article on normative values of TDI of Ascending Aorta, 4D volumetric \& 4D X Strain data on healthy Indian subjects.

Echocardiography is perhaps the most useful non-invasive imaging technique available at present due to its pristine and peerless ability to combine safety and ease with high diagnostic yield. Accurate assessment of cardiac chamber size and function is a key objective of any echocardiographic examination. During echocardiography, such assessment is performed by comparing observed measurements with the normal ranges available for those parameters. The normal values published by ASE/EACVI are currently the most used reference for this purpose [41]. However, these reference values are mostly derived from the western populations, whereas previous studies have demonstrated that ethnicity may significantly affect cardiac chamber dimensions and functions [42, 46]. Accordingly, the applications of ASE/EACVI reference values to other ethnic groups is fraught with the potential to lead to erroneous interpretations. This underscores the need to develop ethnic-specific reference values.

In the present study, we have described normal reference ranges for cardiac chamber size and functions in Indian men and women. It was found that the LV dimensions and volumes were larger in men as compared to women. These findings are consistent with those reported in the western populations (ASE/EACVI guidelines) [41] as well as a migrant (WASE and LOLIPOP studies) or native Indians [43, 44, 47].

Several previous studies have demonstrated that Indians have a smaller cardiac chamber than the western populations [43-45, 47]. Chahal et al. (2010) compared 499 European men and women with 479 Indians living in London who were recruited in the LOLIPOP (London Life Sciences Prospective Population) study [43]. They found that the Indians had significantly smaller LV volumes as compared to the Europeans. More recently, the WASE study has again demonstrated smaller cardiac chamber dimensions in Indians as compared to several other ethnic groups, even though the number of Indians studied was small [47].

Earlier studies have shown that ethnicity is an important determinant of cardiac chamber sizes. Indians have smaller chamber sizes and mildly 
thicker LV walls, not classifiable as hypertrophy based on the thickness, than Europeans but equivalent LVEF [48, 49] It was also observed earlier that LVESVI and LVEDVI indexed to BSA were smaller in Indian Asian men and women compared with their European white counterparts while LVEF was similar between ethnicity- sex subgroups [44]. It was observed that indexing to BSA reduced the LVEDV and LESV differences between Indian measurements and ASE-defined normal values considerably [45]. These references make a strong point for the collection of different population-based normative data useful for comparison and reference by the medical community researchers. Our findings have revealed lower values for global and longitudinal strain in our healthy adult subjects as compared to European and Americans. Whether it is due to smaller LV with thicker walls or is it a racial variation or the study was carried out during the corona pandemic period while all the subjects were wearing face masks throughout their echocardiography workup remains to be answered.

Accurate quantification of LV systolic function has important prognostic implications and is helpful to determine treatment decisions for a variety of therapies. 2D LVEF is the most commonly used echocardiographic parameter to evaluate the LV function in clinical practice. However, measurement of LVEF is limited by geometric structure, image quality, load dependence and poor reproducibility [66]. Therefore, it is necessary to develop a more sensitive and accurate technique to quantify LV systolic function.

2D STE has been validated by cardiac MRI and 3D echocardiography as an effective method to assess LV function [51]. Many previous studies have shown that 2D STE provides more accurate prognostic implications than traditional 2D LVEF in the assessment of a variety of clinical heart diseases, such as heart failure [52, 53], valvular heart disease $[54,55]$, ischemic heart disease [56]. However, 2D STE has the potential limitation of out-of-plane motion tracking of speckles, which can lead to increased noise and reduced accuracy $[57,58]$.

4D echocardiographic techniques, including real-time 3D speckle tracking program and 3D echocardiography allow volumetric analysis and simultaneous measurements of multidirectional components of strain in a single data set. The acquisition of the entire $\mathrm{LV}$ within a single data set allows global assessment of LV longitudinal, circumferential, and radial functions across all myocardial segments [7].

An interesting observation in the assessment of a healthy population was the difference found in the average values of strain between individual segments, as well as different walls and levels of the LV. Functional non-uniformity is a known failure of normal LV that may have a consequence for the validity of the assessment of segmental function [59-62]. Indeed, some differences in the performance measures of segmental wall motion assessment were previously observed between different LV levels, although none were substantial enough to warrant separate cut-off values [61]. In the current study, the general consistency in the magnitude of segmental area strain seems to confirm these previous findings. The longitudinal strain was lower in the midventricular wall compared with the basal and apical levels, as previously noted in an analysis of normal segments inpatient [60]. Moreover, there is considerable heterogeneity in mean longitudinal strain between individual segments. The apical, anterior wall, in particular, demonstrated a surprisingly low mean strain value compared with other segments, which may in part be due to the known difficulty with adequate visualization and tracking of this particularly challenging area of the LV. For these reasons, segment-specific cut-off values are warranted for these strain parameters for the adequate distinction between what is normal and what should be considered pathological, particularly if diagnostic or therapeutic decisions are based on their assessment. Ultimately, future 
clinical studies will determine whether 4D X Strain STE-derived LV strain parameters have a value for diagnosis and prognosis of heart disease in clinical practice.

Multiple studies have evaluated normal strain values with 2D speckle tracking echocardiography (2DSTE), showing a wide reference range of LV strain in apparently normal subjects. [59-62] Moreover, studies have demonstrated discordant results between 2DSTE and 3DSTE, which may be explained by the 3D cardiac motion that is partly lost when imaging in two dimensions. [63-64] Longitudinal and radial strains by 3DSTE are significantly smaller than by 2DSTE. whereas circumferential strain in significantly larger using 3DSTE. In our studies, all the 2D LV strains were lower in men than in women. Recent 2D and 3D speckle tracking echocardiography (STE) studies in healthy populations have shown that GLS is higher in women [65, 67].
The current study provides contemporary normal reference values of 2DE measurements of conventional echocardiographic data, TDI of Ascending Aorta, GLS of LV, and additionally 4D volumetric and 4D X Strain data of GLS, GCS, GCSR, GRS \& GRSR in healthy Indian adults. It demonstrates differences between men and women, different age groups, as well as the functional non-uniformity of the normal LV. These findings are important, because they may signify the necessity for gender, age, and segment-specific normal ranges. We have presented Table 8 . which furnishes the summarized values of the above-mentioned parameters achieved from the present study. Table 8 is particularly meant for contemporary and prospective medical researchers to conceptualize further on these interesting original research findings.

Table-8. Summary of Normal Reference Values of Important Parameters

\begin{tabular}{|c|c|c|}
\hline \multicolumn{3}{|c|}{ Data of Tissue Doppler imaging of Asending Aorta } \\
\hline Variables & Male & Female \\
\hline $\mathrm{AOD}(\mathrm{cm})$ & $2.7 \pm 0.45$ & $2.491 \pm 0.37$ \\
\hline $\operatorname{AOS}(\mathrm{cm})$ & $3.07 \pm 0.49$ & $2.721 \pm 0.40$ \\
\hline Pulsatile Change $(\mathrm{cm})$ & $0.28 \pm 0.21$ & $0.231 \pm 0.14$ \\
\hline $\mathrm{SAO}(\mathrm{cm} / \mathrm{sec})$ & $1.05 \pm 0.30$ & $1.142 \pm 0.40$ \\
\hline $\mathrm{AAO}(\mathrm{cm} / \mathrm{sec})$ & $1.10 \pm 0.37$ & $0.992 \pm 0.35$ \\
\hline $\mathrm{EAO}(\mathrm{cm} / \mathrm{sec})$ & $0.99 \pm 0.33$ & $1.129 \pm 0.39$ \\
\hline Ao Distensbility $(\mathrm{dyn} / \mathrm{cm} 2)$ & $0.0052 \pm 0.00$ & $0.005 \pm 0.00$ \\
\hline Ao Stiffness Index & $3.90 \pm 3.79$ & $5.23 \pm 10.55$ \\
\hline \multicolumn{3}{|c|}{ 2D Global longitudinal Strain data } \\
\hline GLS (\%) & $16.63 \pm 1.91$ & $17.87 \pm 2.13$ \\
\hline \multicolumn{3}{|l|}{ 4D Volumetric data } \\
\hline Sphericity Index d & $0.44 \pm 0.13$ & $0.39 \pm 0.09$ \\
\hline Sphericity Index s & $0.3656 \pm 0.15$ & $0.32 \pm 0.11$ \\
\hline LVEDV d (ml) & $85.23 \pm 18.30$ & $77.95 \pm 15.49$ \\
\hline LVESV s (ml) & $37.8 \pm 8.52$ & $34.62 \pm 10.06$ \\
\hline $\mathrm{EF}(\%)$ & $55.56 \pm 5.53$ & $56.21 \pm 6.58$ \\
\hline $\mathrm{CO}(\mathrm{L} / \mathrm{min})$ & $3.45 \pm 0.83$ & $3.54 \pm 0.97$ \\
\hline $\mathrm{CI}(\mathrm{L} / \mathrm{min} / \mathrm{m} 2)$ & $1.94 \pm 0.42$ & $2.18 \pm 0.56$ \\
\hline \multicolumn{3}{|c|}{ 4D X STRAIN speckle Tracking Echocardiography data } \\
\hline GLS (\%) & $-17.29 \pm 2.71$ & $-19.00 \pm 3.51$ \\
\hline
\end{tabular}




\begin{tabular}{|c|c|c|}
\hline \multicolumn{3}{|l|}{ GCS } \\
\hline at mv level (\%) & $-15.46 \pm 7.10$ & $-14.12 \pm 6.15$ \\
\hline at pap level $(\%)$ & $-20.27 \pm 6.78$ & $-19.69 \pm 7.98$ \\
\hline \multicolumn{3}{|l|}{ GRS } \\
\hline at mv level (\%) & $-24.52 \pm 9.82$ & $-21.92 \pm 8.81$ \\
\hline at pap level $(\%)$ & $-24.4 \pm 10.52$ & $-22.12 \pm 11.00$ \\
\hline \multicolumn{3}{|l|}{ GCSR } \\
\hline at mv level $(1 / \mathrm{sec})$ & $1.78 \pm 0.62$ & $1.97 \pm 0.68$ \\
\hline at pap level $(1 / \mathrm{sec})$ & $1.88 \pm 0.59$ & $2.09 \pm 0.64$ \\
\hline \multicolumn{3}{|l|}{ GRSR } \\
\hline at mv level $(1 / \mathrm{sec})$ & $2.86 \pm 0.97$ & $2.7 \pm 1.04$ \\
\hline at pap level $(1 / \mathrm{sec})$ & $2.3 \pm 0.58$ & $2.89 \pm 1.20$ \\
\hline \multicolumn{3}{|c|}{$\begin{array}{l}\text { TDI=Tissue Doppler Imaging,AOD=Aortic Diastolic Diameter,AOS=Aortic } \\
\text { Systolic Diameter,SAO=Systolic Aortic }\end{array}$} \\
\hline \multicolumn{3}{|c|}{$\begin{array}{l}\text { upper Wall Velocity,EAO=Early diastolic Aortic Upper Wall Velocity } \\
\text { AAO=Late Diastolic Aortic upper Wall velocity }\end{array}$} \\
\hline \multicolumn{3}{|c|}{ GLS=Global Longitudinal Strain,AP=Apical } \\
\hline \multicolumn{3}{|c|}{$\begin{array}{l}\text { GLS: global Longitudinal Strain GCS=Global circumferential } \\
\text { Strain,GRS=Global Radial Strain }\end{array}$} \\
\hline
\end{tabular}

\section{Conclusions}

Normal ranges of tissue Doppler imaging of Ascending Aorta, global and segmental longitudinal LV strain using 2D STE and additionally 4D volumetric data and GCS, GCSR, GRS, GRSR by 4D X strain echocardiography in healthy Indian adults are being presented for clinical use. Differences in the magnitude of LV strain are present in men and women, as well as between different segments, walls, and levels as part of the functional non-uniformity of normal LV.

\section{Acknowledgement}

We thank Mrs. Sadhna Mehrotra for her incredible support by providing numerous healthy subjects for the present study through her NGO- MOTHER \& CHILD WELFARE ORGANISATION. Our earnest, heartfelt gratitude to Mrs. Laxmi for her tireless efforts in typing the manuscript repeatedly throughout all the phases of the study.

\section{Conflicts of Interest}

These are no conflicts of interest. 


\section{References}

[1] Quninones MA, Greenberg BH, Kopelen HA, Koilpillai C, Limacher MC, Shindler DM, et al. Echocardiographic predictors of clinical outcome in patients with left ventricular dysfunction enrolled in the SOLVD registry and trials: Significance of left ventricular hypertrophy, Studies of left ventricular dysfunction. J Am CollCardiol2000; 35(5):12371244.

[2] Thune JJ. Kober L, Pfeffer MA, Skali H, Anavekar NS, Bourgoun M, et al. Comparison of regional versus global assessment of left ventricular function in patients with left ventricular dysfunction, heart failure, or both after myocardial infarction; the valsartan in acute myocardial infarction echocardiographic study. J Am Soc Echocardiogr 2006; 19(12):1462-1465.

[3] Kocabay G, Muraru D, Peluso D, Cucchini U, Mihaila S, Padayattil-Jose Sanjay Pandey MD., et al. Normal left ventricular mechanics by twodimensional speckle-tracking echocardiography. Reference values I healthy adults. Rev Esp Cardiol (Engl Ed)2014; 67(8):651-658.

[4] Quinones MA, Douglas PS, Foster E, Gorcsan J 3rd, Lewis JF, Pearlman AS, et al.; American Society of Echocardiography; Society of Cardiovascular Anesthesiologists; Society of Pediatric Echocardiography. ACC/AHA clinical competence statement on echocardiography: A report of the American College of Cardiology/ American Heart Association/ American College of physiciansAmerican Society of Internal Medicine Task Force on Clinical Competence. J Am Soc-Echocardiogr.2003; 16(4):379-402.

[5] Nakatani S. Left ventricular and twist: Why should we learn? J Cardiovasc Ultrasound 2011: 19(1): 1-6.

[6] Poveda F, Git D, Marti E, Andaluz A, Ballester M, Carreras F, Helical Structure of the cardiac ventricular anatomy assessed by diffusion tensor magnetic resonance imaging with multiresolution tractography. Rev Esp Cardiol (Engl Ed)2013; 66(10): 782-790.

[7] Muraru, D.; Niero, A.; Zanella, H.R.; Cherata, D.; Badano, L.P. Three-dimensional speckle-tracking echocardiography: Benefits and limitation of integrating myocardial mechanics with threedimensional imaging. Cardiovasc. Diagn. Ther. 2018, 8, 101-117.

[8] Kang Y, Sun MM, Cui J, Chen HY, Su YG, Pan $\mathrm{CZ}$, et al. Three-dimensional speckle tracking echocardiography for the assessment of left ventricular function and mechanical dyssynchrony. Acta Cardiol 2012; 67(4):423-430.

[9] Chen R, Wu X, Shen LJ, Wang B, Ma MM, Yang $\mathrm{Y}$, et al. Left ventricular myocardial function in hemodialysis and nondialysisuremia patients: A three-dimensional speckle-tracking echocardiography study. PLoS One 2014; 9(6):e100265.

[10]Zhu M, Streiff C, Panosian J, Zhang Z, Song X, Sahn DJ, et al. Regional Strain determination and myocardial infarction detection by three-dimensional echocardiography with varied temporal resolution Echocardiography 2015; 32(2):339-348.

[11]Zhu M, Streiff C, Panosian J, Roundhill D, Lapin M, Tutschek B, et al. Evaluation of stroke volume and ventricular mass in a fetal heart model: A novel fourdimensional echocardiographic analysis. Echocardiography 2014; 31(9): 1138-1145.

[12] Jenkins C, Leano R, Chan J. Marwick TH. Reconstructed versus real-time 3-dimensional echocardiography: Comparison with magnetic resonance imaging. J Am Soc Echocardiogr 2007; 20(7): 862-868.

[13] Jenkins C, Leano R, Chan J, Marwick TH. Reconstructed versus real-time 3-dimensional echocardiographic measurements of left ventricular parameters using real-time three-dimensional echocardiography. J Am Coll Cardiol 2004; 44 (4):878-886.

[14]Pedrizzetti G, Mangual J and Tonti G. On the geometrical relationship between global longitudinal strain and ejection fraction in the evaluation of cardiac contraction. J Biomech. 2014 47:746-9.

[15] Stampehi MR, Mann DL, Nguyen JS, Cota F, Colmenares C, and Dokainish H. Speckle strain echocardiography predicts outcome in patients with heart failure with both depressed and preserved left ventricular ejection fraction. Echocardiography. $2015 ; 32: 71-8$. 
[16]Perk G, Tunick PA and Kronzon I. Non-Doppler two-dimensional strain imaging by echocardiography from technical consideration to clinical application. J

Am Soc Echocardiogr.2007; 20:234-43.

[17] Mizuguchi Y, Oishi Y, Miyoshi H, luchi A, Nagase $\mathrm{N}$ and Oki $\mathrm{T}$. the functional role of longitudinal, circumferential, and radial myocardial deformation for early impairment of left ventricular contraction and relaxation in patients with cardiovascular risk factors: a study with twodimensional strain imaging. J Am Soc Echocardiogr. 2008; 21:1138-44.

[18] Share BL, La Gerche A, Naughton GA, Obert P, and Kemp JG. Young Women with Abdominal Obesity Have Subclinical Myocardial Dysfunction. Can J cardiol 2015; 31:1195-201.

[19] Yingchoncharoen T, Agarwal S, Popovic ZB, and Marwick TH. Normal ranges of left ventricular strain: a meta-analysis. J Am Soc Echocardiogr. 2013; 26:185-91.

[20] Kleijn SA, Pandian NG, Thomas JD, Perez de Isla L, Kamp O, Zuber M, Nihoyannopoulos P, Forster T, Neser HJ, Geibel A, Gorissen W and Zamorano JL. Normal reference values of left strain using three-dimensional speckle tracking echocardiography: result from a multicenter study. Eur Heart J Cardiovasc Imaging:2015; 16:410-6. [21]Bernard A, Addetia K, Dulgheru R, Caballero L, Sugimoto T, Akhaladze N, Athanasopoulos GD, Barone D, Baroni M, Cardim N, Hristova K, Ilardi F, Lopez T, de la Morena G, Popescu BA, Penicka M, Ozyigit T, David Rodrigo Carbonero J, van de Veire N, Stephan Von Bardeleben R, vinereanu D, Luis Zamorano J, Martinez C, Magne J, Cosyns B, Donal E, Habib G, Badano LP, Lang RM and Lancellotti P, $3 \mathrm{D}$ echocardiographic reference ranges for normal left ventricular and strain results from the EACVI NORRE study. Eur Heart $\mathrm{J}$ Cardiovasc Imaging 2017; 18:475-483.

[22] Cheng S, Larson MG, McCabe EL, Osypiuk E, Lehman BT, Stanchev P, Aragam J, Benjamin EJ, Solomon SD and Vasan RS. Age- and sex- based reference limits and clinical correlates of myocardial strain and synchrony: the Framingham Heart study. Circ Cardiovasc Imaging 2013; 6:692-9.
[23] Menting ME, mcGhie JS, Koopman LP, Vletter WB, Helbing WA, van de Bosch AE and RoosHesselink JW. Normal myocardial strain values using 2D speckle tracking echocardiography in healthy adults aged 20 to 72 years. Echocardiography .2016;33:1665-1675.

[24]Dalen H, Thorstensen A, Aase SA, Ingul CB, Trop H, Vatten LJ, and Stoylen A. Segmental and global longitudinal strain and strain rate based on echocardiography of 1266 healthy individuals: the HUNT study in Norway. Eur J Echocardiogr .2010; 11:176-83.

[25] Moreira HT, Nwabuo CC, Armstrong AC, Kishi S, Gjesdal O, Reis JP. Schreiner PJ, Liu K, Lewis CE, Sidney S, Gidding SS, Lima JAC, and AmbaleVenkatesh B. Reference Ranges and Regional Patterns of Left Ventricular Strain and Strain Rate Using Two-Dimensional Speckle-Tracking Echocardiography in a Healthy Middle-Aged Black and White Population: The CARDIA study. J Am Soc Echocardiogr.2017;30:647-658 e2.

[26] Park JH, Lee JH, Lee SY, Choi JO, Shin MS, Kim MJ, Jung HO, Park JR, Sohn IS, Kim H, Park SM, Yoo NJ, Choi JH, Kim HK, Cho GY, Lee MR, Park JS, Shim CY, Kim DH, Shin DH, Shin GJ, Shin SH, Kim KH, Kim WS, and Park SW. Normal 2Dimensional Strain Values of the Left Ventricular: A Substudy of the Normal Echocardiographic Measurements in Korean Population Study. J Cardiovasc Ultrasound.2016;24:285-293.

[27] Kaku K, Takeuchi M, Tsang W, Takigiku K, Yasukochi S, Patel AR, Mor-Avi V, Lang RM and Otsuji Y. Age-related normal range of left ventricular strain and torsion using three-dimensional speckletracking echocardiography. J Am Soc Echocardiogr.2014;27:55-64.

[28]Liu CY, Lai S, Kawel-Boehm N, Chahal H, Ambale-Venkatesh B, Lima JAC and Bluemke DA. Healthy aging of the left ventricle in relationship to cardiovascular risk factors: The Multi-Ethnic Study of Atherosclerosis (MESA). PLoS One.2017; 12: e0179947.

[29]Bjornstad P, Truong U, Pyls L, Dorosz JL, CreeGreen M, Baumgartner A, Coe G, Regensteiner JG, Reusch JE and Nadeau KJ. Youth with type 1 diabetes have worse strain and less pronounced sex 
differences in early echocardiographic markers of diabetic. Cardiomyopathy compared to their normoglycemic peers: A RESistance to Insulin in Type 1 ANd Type 2 diabetes (RESISTANT) Study. J Diabetes Complications. 2016; 30:1103-10.

[30] Szelenyi Z, Fazakas A, Szenasi G, Tegze N, Fekete B, Molvarec A, Hadusfalvy-Sudar S, Janosi O, Kiss M, Karadi I and Vereckei A. The mechanism of reduced longitudinal left ventricular systolic function in hypertensive patients with normal ejection fraction. J Hypertens. 2015; 33:1962-9; discussion 1969.

[31]Huang J, Yan ZN, Rui YF, Fan L, Shen D and Chen DL. Left ventricular Systolic Function Changes in Primary Hypertension Patients Detected by the Strain of Different Myocardium Layers. Medicine (Baltimore).2016;95: e2440.

[32] Almeida AL, Teixido-Tura G, Choi EY, Opdahi A, Fernandes VR, Wu CO, Bluemke DA and Lima JA. Metabolic syndrome, strain, and reduced myocardial function: multi-ethnic study of atherosclerosis. Arq Bras Cardiol. 2014; 102:327-35. [33] Pascual M, Pascual DA, Soria F, Vicente T, Hernandez AM, Tebar FJ and Valdes M. Effects of isolated obesity on systolic and diastolic left ventricular function. Heart. 2003; 89:1152-6.

[34] Friedewald WT, Levy RI, Fredrickson DS. Estimation of the concentration of low densitylipoprotein in plasma, without use of the preparative ultracentrifuge. Clin Chem. 1972; 18:499-502.

[35] Wagner M, Tiffe T, Morbach C, Gelbrich G, Stork S, Heuschmann PU and Consortium S. characteristics and Course of Heart Failure Stages A$B$ and Determinants of Progressiondesign and rationale of the STAAB cohort study. Eur J Prev Cardiol. 2017; 24:468-479.

[36] Morbach C, Gelbrich G, at al. Impact of acquisition and interpretation on total inter-observer variability in echocardiography: results from the quality assurance program of the STAAB cohort study. Int J Cardiovasc Imaging. 2018.

[37] Bia D, Aguirre I, Zocalo Y, Devera L, Cabrera Fischer E, Armentano R. [Regional differences in velocity, elasticity and wall buffering function in systemic arteries: pulse wave analysis of the arterial pressure-diameter relationship]. Rev Esp Cardiol. 2005; 58:167-74.

[38] Lehmann ED. Non invasive measurements of aortic stiffness: methodological considerations. Pathol Biol. 1999; 47:716-30.

[39] Lantelme P, Mestre C, Lievre M, Gressard A, Milon $\mathrm{H}$. Heart rate $\mathrm{AN}$ important confounder of pulse wave velocity assessment Hypertension. 2002; 39:1083-7.

[40]Benetos A, Laurent S, Hoeks AP, Boutouyrie $\mathrm{PH}$, Safar ME. Arterial alterations with ageing and high blood pressure: a non-invasive study of carotid and femoral arteries. Arterioscler Thromb. 1993; 13:90-7.

[41]Lang RM, Badano LP, Mor-Avi V et al (2015) Recommendations for cardiac chamber quantification by echocardiography in adults: an update from the American Society of Echocardiography and the European Association of Cardiovascular Imaging. J Am Soc Echocardiogr 28:1-39.

[42] Ethnic-Specific Normative Reference Values for Echocardiographic LA and, size LV (2015) Mass, and systolic functions: \&nbsp; the EchoNoRMAL study.JACC Cardiovas Imaging 8:656-665.

[43] Chahal NS, Lim TK, Jain P, Chmabers JC, Kooner JS, Senior R (2010) Ethnicity-related differences in left ventricular functions, structure, and geometry: a population study of UK Indian Asian and European white subjects. Heart 96:466-471.

[44] Chahal NS, Lim TK, Jain P. Chmabers JC, Kooner JS, Senior R (2012) Population-based references values for 3D echocardiographic LV volumes and ejection fraction. JACC Cardiovasc Imaging 5:1191-1197.

[45]Bansal M, Mohan JC, Sengupta SP (2016) Normal echocardiographic measurements in Indian adults: how different are we from the western populations? A pilot study. Indian Heart J 68:772775.

[46] Poppe KK, Doughty RN, Walsh HJ, Triggs CM, Whalley GA (2014) A comparison of the effects of indexation on standard echocardiography measurements of the left heart in a healthy multiracial population. Int J Cardiovasc Imaging 30:749758. 
[47] Asch FM, Miyoshi T, Addetia K et al (2019) Similarities and differences in left ventricular size and function among races and nationalities: results of the world alliances of echocardiography normal values study. J Am Soc Echocardiogr 32:1396-1406. [48]Chahal NS, Lim TK, Jain P, Chambers JC, Senior R. Population-based reference values for $3 \mathrm{D}$ echocardiographic LV volumes and ejection fraction JACC Cardiovasc Imaging. 2012; 5:1191-1197.

[49] Bansal M, Mohan JC, Sengupta SP. Normal echocardiographic measurements in Indian adults: how different are we from the western populations? A pilot study. Indian Heart J. 2016; 68:772-775. [50]Luis SA, Yamada A, Khandheria BK, Speranza $\mathrm{V}$, Benjamin $\mathrm{A}$, Ischenko $\mathrm{M}$, et al. Use of threedimensional speckle-tracking echocardiography for quantitative assessment of global left ventricular function: A comparative study of three-dimensional echocardiography. J Am Soc Echocardiogr 2014;27 (3):285-291.

[51]Brown J, Jenkins C, Marwick TH, Use of myocardial strain to assess global left ventricular function: a comparison with cardiac magnetic resonance and 3-dimensional echocardiography. Am Heart J. 2009; 157(1):102. e1-e5.

[52] Mignot A, Donal E, Zaroui A, Reant P, Saleem

A, Hamon C, et al. Global longitudinal strain as a major predictor of cardiac events in patients with depressed left ventricular function: A multicenter study. J Am Soc Echocardiogr 2010; 23(10):10191024.

[53] Cho GY, Marwick TH, Kim HS, Kim MK, Hong $\mathrm{KS}$, Oh DJ. Global2-dimensional strain as a new prognosticator in patients with heart failure. $\mathbf{J}$ Am Coll Cardiol 2009; 54(7):618-624.

[54] Kearney LG, Lu K, Ord M, Patel SK, Profitis K, Matalanis G, et al. Global longitudinal strain is a strong independent predictor of all-cause mortality in patients with aortic stenosis. Eur Heart J Cardiovasc Imaging 2012; 13(10):827-833.

[55]Dahi JS, Videbaek L, Poulsen MK, Rudbaek TR, Pellikka PA, Moller JE, Global Strain in severe aortic valve stenosis: Relation to clinical outcome after aortic valve replacement. Circ Cardiovasc Imaging 2012;5(5):613-620.
[56] Woo JS, Kim WS, Yu TK, Ha SJ, Kim SY, Bae $\mathrm{JH}$ et al. Prognostic value of serial global longitudinal strain measured by two-dimensional speckle tracking echocardiography in patients with ST-segment elevation myocardial infarction. Am J Cardiol 2011; 108(3):340-347.

[57] Chen X, Xie H, Erkamp R, Kim K, Jia C, Rubin JM, et al. 3-D correlation-based speckle tracking. Ultrason Imaging 2005; 27(1):21-36.

[58] Mor-Avi V, Lang RM, Badano LP, Belohlavek M, Cardim NM, Derumeaux G, et al. Current evolving echocardiographic techniques for the quantitative evaluation of cardiac mechanics: ASE/EAE consensus statement on methodology and indications andorsed by the Japanese Society of Echocardiography. J Am Soc Echocardiogr 2011;24(3):277-313.

[59] Perez de Isla L, Balcones DC, Fernandez-Golfin C, Marcos-Alberca P, Almeria C Rodrigo JL et al. Three-dimensional-wall motion tracking; a new and faster tool for myocardial strain assessment; comparison with two-dimensional-wall motion tracking. J Am Soc Echocardiogr 2009; 22:325-30. [60] Maffessanti F, Nesser HJ, Weinert L, SteringerMascherbauer R, Niel J. Gorissen W et al. Quantitative evaluation of regional left ventricular function using three-dimensional speckle Tracking echocardiography in patients with and without heart disease. Am J cardiol 2009;1041755-62.

[61] Kleijn SA, Aly MF, Terwee CB, van Rossum AC, Kamp O. Three-dimensional speckle tracking echocardiography for automatic assessment of global and regional left ventricular function based on area strain. J Am Soc Echocardiogr 2011; 24:314-21. [62] Marwick TH, Leano RL, Brown J, Sun JP, Hoffmann R, Lysyansky P et al. Myocardial strain measurements with 2-dimensional speckle-tracking echocardiography: definition of normal range. JACC Cardiovasc Imaging 2009; 2:80-4.

[63] Maffessanti F, Nesser HJ, Weinert L, SteringerMascherbauer R, Niel J, Gorissen $\mathrm{W}$ et al. Quantitative evaluation of regional left ventricular function using three-dimensional speckle tracking echocardiography in patients with and without heart disease. Am J Cardiol 2009; 104:1755-62. 
[64] Saito K, Okura H, Watanabe N, Hayashida A, Obase K, lmai $\mathrm{K}$ et al. Comprehensive evaluation of left ventricular strain using speckle tracking echocardiography in normal adults: comparison of three-dimensional and two-dimensional approaches. J Am Soc Echocardiogr 2009; 22:1025-30.

[65] Bernard A, Addettia K, Dulgheru R, Caballero L, Sugimoto T, Akhaladze $\mathrm{N}$ et al. 3D echocardiographic reference ranges for normal left ventricular volume and strain: results from the EACVI NORRE study. Eur Heart J Cardiovasc Imaging 2017; 18:475-83.
[66] Kocabay G, Muraru D, Peluso D, Cucchini U, Mihaila S, Padayattil-Jose $\mathrm{S}$ et al. Normal left ventricular mechanics by two-dimensional speckletracking echocardiography. References values in healthy adults. Rev Esp Cardiol (Engl Ed) 2014:67:651-8.

[67] Muraru D, Cucchini U, Mihaila S, Miglioranza MH, Aruta P, Caralli G et al. Left ventricular myocardial strain by three-dimensional speckletracking echocardiography in healthy subjects: reference values and analysis of their physiologic and technical determinants. J Am Soc Echocardiogr 2014; 27:858-71. 